\title{
ANALISIS DAMPAK LALU LINTAS PEMBANGUNAN MALL LAGOON AVENUE SUNGKONO TERHADAP KINERJA SIMPANG DI JALAN MAYJEND SUNGKONO - HR MUHAMMAD SURABAYA
}

\author{
Sri Awiyaningsih ${ }^{1}$, Hary Moetriono², Sri Wiwoho Mudjanarko ${ }^{3}$ \\ 1,2Teknik Sipil \\ Universitas 17 Agustus 1945 Surabaya \\ e-mail : ${ }^{1}$ awiyaningsih1805@gmail.com, ${ }^{2}$ hary_moetriono@yahoo.com \\ ${ }^{3}$ Teknik Sipil \\ Universitas Narotama, Surabaya, Indonesia \\ e-mail : sri.wiwoho@narotama,ac,id
}

Diterima: 1 Agustus 2018. Disetujui : 8 Desember 2018. Dipublikasikan : 10 Desember 2018

(C)2018 -TESJ Fakultas Teknik Universitas Maarif Hasyim Latif. Ini adalah artikel dengan

akses terbuka di bawah lisensi CC BY 4.0 (https://creativecommons.org/licenses/by/4.0/)

\begin{abstract}
ABSTRAK
Kota Surabaya sebagai ibu kota provinsi Jawa Timur adalah kota dengan potensi yang cukup besar dilihat dari sistem transportasinya dan dalam pembangunan bangunan - bangunan yang memberikan nilai lebih terhadap berbagai peluang bisnis dan investasi. Pembangunan gedung perkantoran, apartemen dan mall di Kota Surabaya memacu tingkat perubahan intensitas lalu lintas. Mall merupakan salah satu bangunan yang perkembangannya sangat baik di Kota Surabaya. Pembangunan Mall terbaru yang sedang berjalan salah satunya adalah Mall Lagoon Avenue Sungkono yang terletak di Jl KH Abdul Wahab Siamin yang lokasinya berdekatan dengan persimpangan Jl Mayjend Sungkono - HR Muhammad, karena lokasi mall yang cukup strategis tentunya akan berdampak pada kondisi tarikan dan bangkitan lalu lintas di sekitar lokasi pembangunan mall. Maka dari itu perlu diadakannya analisa dampak lalu lintas di persimpangan Jl Mayjend Sungkono - HR Muhammad akibat pembangunan Mall Lagoon Avenue Sungkono Surabaya. Pembangunan Mall Lagoon Avenue Sungkono akan berdampak pada ruas jalan dan persimpangan yang ada disekitar lokasi, penulis menggunakan metode regresi linear dalam melakukan analisis yang diawali dengan pengumpulan data primer yaitu survey lapangan, geometric, arus lalu lintas, volume masuk dan keluar kendaraan pada maal pembanding dan data sekunder serta volume bangkitan akibat pembangu nan Mall Lagoon Avenue Sungkono. Dari hasil analisa data didapatkan jumlah bangkitan kendaraan Mall Lagoon Avenue Sungkono Surabaya adalah 104 kend/jam untuk MP dan 150 kend/jam untuk SM. Dan jumlah derajat kejenuhan terbesar terdapat pada jam puncak sore Jl Mayjend Sungkono - HR Muhammad sebesar 0,71 .
\end{abstract}

Kata kunci: transportasi, ruas jalan, persimpangan dan tarikan bangkitan

\section{PENDAHULUAN}

Transportasi merupakan kebutuhan turunan akibat adanya aktivitas ekonomi, sosial, budaya dan sebagainya. Kota Surabaya sebagai ibu kota provinsi Jawa Timur adalah kota dengan potensi yang cukup besar dilihat dari sistem transportasinya dan dalam pembangunan bangunan-bangunan yang memberikan nilai lebih terhadap berbagai peluang bisnis dan investasi. Perubahan tata guna lahan yang merupakan salah satu faktor yang mempengaruhi tingkat kemacetan dalam kota. Persimpangan di Jalan Mayjend Sungkono merupakan salah satu persimpangan yang cukup padat di Kota Surabaya, kondisi persimpangan akibat pembangunan Mall Lagoon Avenue Sungkono pada saat ini belum terlihat bermasalah. Namun, lambat laun masalah lalu lintas akan muncul seiring dengan beroperasinya Mall Lagoon Avenue Sungkono yang mungkin akan mengakibatkan terjadinya bangkitan volume lalu lintas di persimpangan yang ada di sekitar Mall Lagoon Avenue Sungkono. Mall Lagoon Avenue Sungkono sendiri berada di area Jl HR Muhammad dan Mayjend Sungkono yang diprediksi akan menimbulkan bangkitan lalu lintas dan akan menimbulkan tambahan volume lalu lintas yang membebani lalu lintas di sekitaran lokasi yang mana pada kondisi saat ini (eksisting) sudah mulai menunjukkan terjadinya kemacetan khususnya pada jam sibuk. Dari gambaran permasalahan, dapat disimpulkan bahwa untuk meminimalisir terjadinya permasalahan lalu lintas akibat adanya Pembangunan Mall Lagoon Avenue Sungkono, maka perlu dilakukan studi Analisis Dampak Lalu Lintas (Andalalin) sebagai upaya pengendalian rekayasa lalu lintas untuk meminimalisir terjadinya 


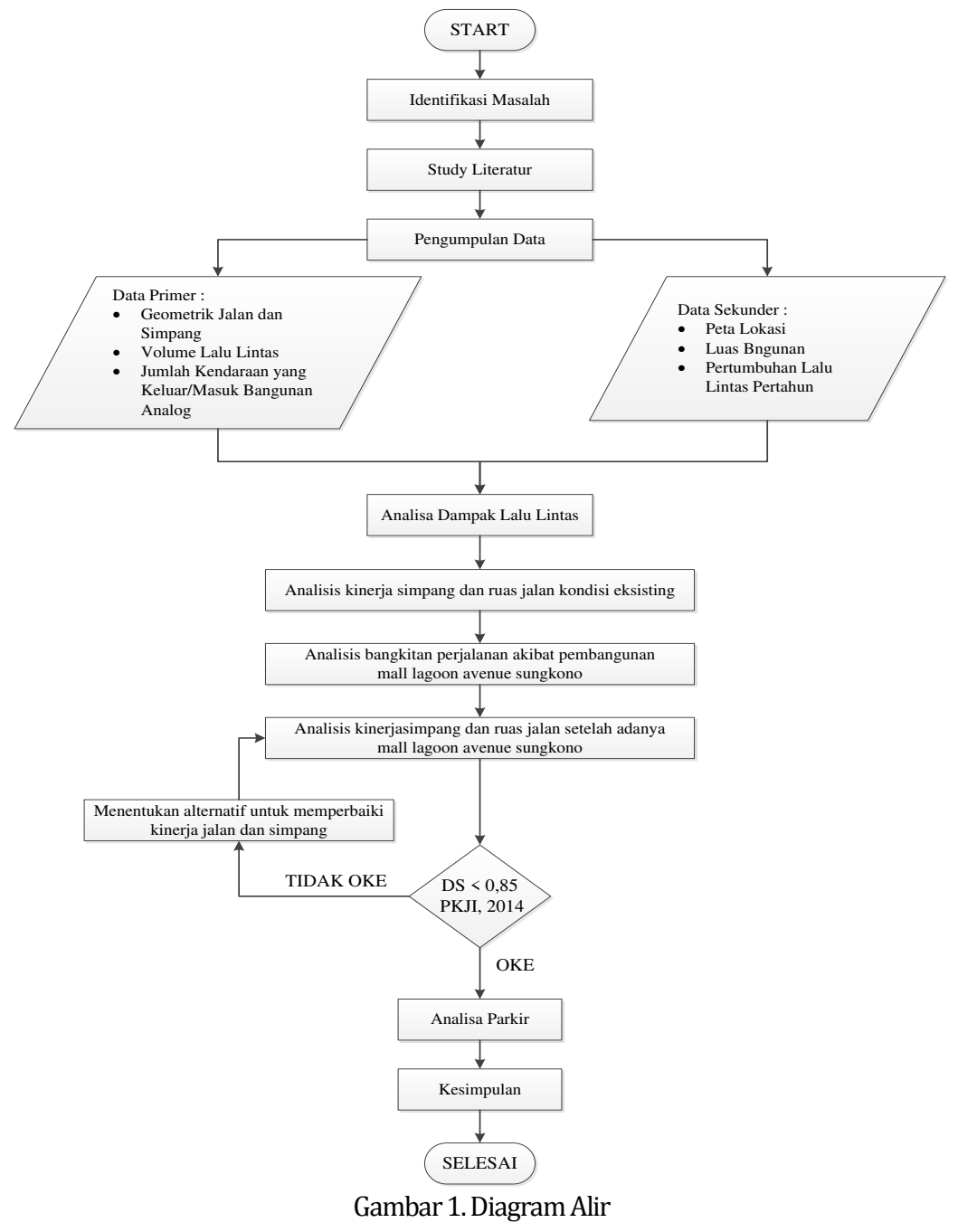

penurunan tingkat pelayanan, kinerja ruas dan kinerja simpang di sekitar wilayah studi.

\section{METODE PENELITIAN}

Lokasi studi untuk penelitian ini adalah Mall Lagoon Avenue dengan spesifikasi bangunan sebagai berikut:

Nama

Lokasi

: Mall Lagoon Avenue Sungkono

: Persimpangan CBD

Jl HR Muhammad-Mayjend Sungkono

Luas Tanah : $8.980 \mathrm{~m}^{2}$

Kategori Bangunan : Mall

Jumlah Bangunan ： 4 lantai

\section{HASIL DAN PEMBAHASAN}

Hasil perhitungan jumlah kendaraan keluar dan masuk di Mall Lagoon Avenue Sungkono dengan metode regresi linier sederhana didapatkan beberapa persamaan berikut :

Mobil penumpang masuk dan keluar Mall Lagoon Avenue Sungkono
Dari Tabel 1, dapat ditarik satu fungsi regresi linier berganda untuk menganalisa hubungan antara jumlah lantai dan jumlah kendaraan masuk keluar bangunan analog dalam Gambar 2.

Tabel 1. Data Perhitungan Regresi MP

\begin{tabular}{lcc}
\hline \multicolumn{1}{c}{ Nama mall } & $\begin{array}{c}\text { Jumlah } \\
\text { lantai }\end{array}$ & $\begin{array}{c}\text { Total kendaraan mobil } \\
\text { penumpang (MP) masuk keluar }\end{array}$ \\
\hline East coast center & 8 & 96 \\
\hline Pakuwon trade center & 6 & 92 \\
\hline Ciputra world surabaya & 6 & 92 \\
\hline Surabaya town square & 4 & 75 \\
\hline City of tomorrow & 4 & 80 \\
\hline Lagoon avenue sungkono & 4 & $X$ \\
\hline
\end{tabular}

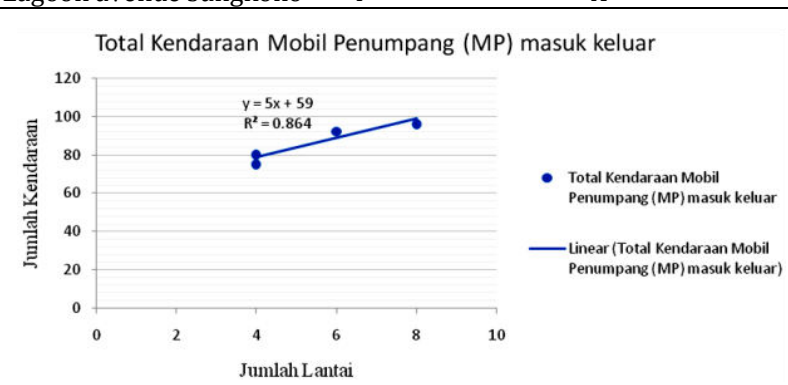

Gambar 2. Grafik Hubungan Jumlah MP Kendaraan $(y)$ dan Jumlah Lantai $(x)$ 
Dalam mengolah data volume bangkitan dari bangunan analog dengan menggunakan metode regresi linier sederhana, yaitu :

$$
y=a x+b
$$

dengan

$$
\begin{array}{ll}
y & : \text { total volume kendaraan keluar masuk bangunan } \\
& \text { analog } \\
a \operatorname{dan} b & : \text { konstanta } \\
x & : \text { jumlah kamar }
\end{array}
$$

Maka didapatkan hasil perhitungan :

$$
\begin{aligned}
\mathrm{MP} & =5 x+59 \\
& =5(4)+59 \\
& =92 \mathrm{kend} / \mathrm{jam} \\
\mathrm{SM} & =4.9643 x+121 \\
& =4.9643(4)+121 \\
& =141
\end{aligned}
$$

Hasil perhitungan regresi linier MP dan SM yang masuk dan keluar dari Mall Lagoon Avenue Sungkono dapat dilihat pada Tabel 2.

Tabel 2. Kendaraan Masuk dan Keluar Pada Jam Puncak Mall Lagoon Avenue Sungkono

\begin{tabular}{c|c|c|c}
\hline \multirow{2}{*}{ Nama Mall } & \multicolumn{2}{|c|}{ Jumlah Kendaraan/jam } & \multirow{2}{*}{ Jumlah } \\
\cline { 2 - 3 } & MP & SM & Lantai \\
\cline { 2 - 3 } & $\begin{array}{c}\text { Masuk } \\
\text { Keluar }\end{array}$ & $\begin{array}{c}\text { Masuk } \\
\text { Keluar }\end{array}$ & \\
\hline Lagoon Avenue Sungkono & 92 & 141 & 4 \\
\hline
\end{tabular}

Tabel 3. Volume kendaraan masuk keluar Mall Lagoon Avenue Sungkono Surabaya

\begin{tabular}{c|c|c|c|c}
\hline \multirow{2}{*}{ Nama Mall } & \multicolumn{4}{|c}{$\begin{array}{c}\text { Asumsi Jumlah Kendaraan Masuk } \\
\text { Keluar/Jam }\end{array}$} \\
\cline { 2 - 5 } & \multicolumn{3}{|c}{ Masuk } & \multicolumn{3}{c}{ Keluar } \\
\cline { 2 - 5 } & MP & SM & MP & SM \\
\hline $\begin{array}{c}\text { Lagoon Avenue } \\
\text { Sungkono }\end{array}$ & 46 & 71 & 46 & 71 \\
\hline
\end{tabular}

Pembebanan volume bangkitan kendaraan masuk keluar Mall Lagoon Avenue Sungkono pada simpang bersinyal

Dari hasil yang diperoleh dari perhitungan volume kendaraan masuk keluar Mall Lagoon Avenue Sungkono, selanjutnya dilakukan perhitungan presentase volume kendaraan masuk dan keluar pada jam puncak dan mengambil ratarata presentase dari bangunan analog. Dari hasil perhitungan tersebut akan diketahui jumlah volume kendaraan yang akan masuk dan keluar pada Mall Lagoon Avenue Sungkono Surabaya dari simpang bersinyal Jl Mayjend Sungkono-Jl KH Abdul Wahab Siamin-Jl HR Muhammad pada saat jam puncak pagi.

\section{Analisis Data Jumlah Kendaraan di Kota Surabaya} Pertumbuhan volume lalu lintas untuk tahun yang sudah direncanakan tergantung dari pertumbuhan kendaraan. Hasil dari perhitungan faktor pertumbuhan volume lalu lintas masingmasing kendaraan dikalikan dengan kapasitas kendaraan untuk mengetahui kapasitas kendaraan memenuhi sampai tahun rencana $(x)$ dengan nilai pertumbuhan lalu lintas 5\% per tahun.

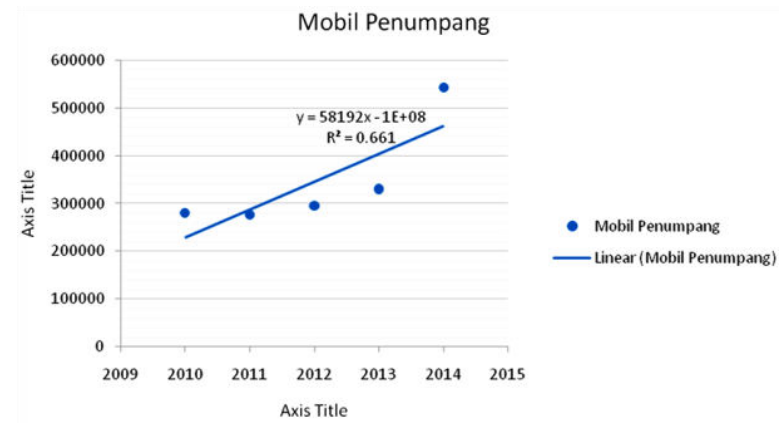

Gambar 3. Pertumbuhan Mobil Penumpang (MP)

Dari hasil analisa regresi jumlah mobil penumpang diperoleh persamaan berikut:

$$
\begin{aligned}
& y=58192.3 x-116738378.4 \\
& R^{2}=0.66
\end{aligned}
$$

\section{PENUTUP}

\begin{tabular}{|c|c|c|c|c|c|c|c|c|c|c|c|c|}
\hline No & Nama Ruas & Batas Ruas & Kelas Jalan & Tipe Ruas & Periode & Arah Pergerakan & MP & $\mathrm{KB}$ & SM & $\begin{array}{l}\text { Volume } \\
\text { Tahun } \\
2018 \\
\end{array}$ & $\begin{array}{c}\text { Kapasitas } \\
\text { (C) }\end{array}$ & $\begin{array}{l}\mathrm{Dj}= \\
\mathrm{Q} / \mathrm{C}\end{array}$ \\
\hline \multirow{6}{*}{1} & \multirow{6}{*}{$\begin{array}{l}\text { Jl KH Abdul Wahab } \\
\text { Siamin }\end{array}$} & \multirow{6}{*}{$\begin{array}{c}\text { Jl KH Abdul } \\
\text { Wahab Siamin } \\
\text { - Jl KH Abdul } \\
\text { Wahab Siamin } \\
\text { - Jl HR } \\
\text { Muhammad }\end{array}$} & \multirow{6}{*}{$\begin{array}{l}\text { Kolektor } \\
\text { Sekunder }\end{array}$} & \multirow{6}{*}{$4 / 2 \mathrm{~T}$} & \multirow{2}{*}{ Puncak Pagi } & Selatan - Utara & 807 & 13 & 3530 & 1705.1 & 3376 & 0.51 \\
\hline & & & & & & Utara - Timur & 988 & 22 & 3344 & 1850.4 & 3376 & 0.55 \\
\hline & & & & & \multirow{2}{*}{ Puncak Siang } & Selatan - Utara & 841 & 15 & 3728 & 1791 & 3376 & 0.53 \\
\hline & & & & & & Utara - Timur & 1101 & 57 & 3590 & 2066.9 & 3376 & 0.61 \\
\hline & & & & & \multirow{2}{*}{ Puncak Sore } & Selatan - Utara & 893 & 11 & 4236 & 1965.2 & 3376 & 0.58 \\
\hline & & & & & & Utara - Timur & 914 & 22 & 3581 & 1835.65 & 3376 & 0.54 \\
\hline \multirow{3}{*}{2} & \multirow{3}{*}{ Jl Mayjend Sungkono } & \multirow{3}{*}{$\begin{array}{c}\text { Jl Mayjend } \\
\text { Sungkono - Jl } \\
\text { HR Muhammad }\end{array}$} & \multirow{3}{*}{$\begin{array}{c}\text { Arteri } \\
\text { Primer }\end{array}$} & \multirow{3}{*}{$4 / 2 \mathrm{~T}$} & Puncak Pagi & Barat - Timur & 3738 & 18 & 7996 & 5758.6 & 5076 & 1.13 \\
\hline & & & & & Puncak Siang & Barat - Timur & 3123 & 61 & 7023 & 4951.95 & 5076 & 0.98 \\
\hline & & & & & Puncak Sore & Barat - Timur & 3498 & 47 & 7817 & 5508.65 & 5076 & 1.09 \\
\hline
\end{tabular}

Kondisi kinerja lalu lintas yang terjadi di simpang bersinyal akibat adanya pembangunan Mall Lagoon Avenue Sungkono Surabaya dengan nilai derajat kejenuhan (Dj):

a. Jl Mayjend Sungkono-HR Muhammad sebesar 0,71

b. Jl Mayjend Sungkono-Jl KH Abdul Wahab Siamin sebesar 0,33

c. Jl KH Abdul Wahab Siamin-Jl HR Muhammad sebesar 0,26

Tabel 4. Volume Lalu Lintas Setelah Penambahan Kendaraan Masuk dan Keluar Mall Lagoon Avenue Sungkono Surabaya pada Tahun 2023 


\section{d. Jl KH Abdul Wahab Siamin (arah proyek)} sebesar 0,23

Dari hasil perhitungan tersebut dapat disimpulkan nilai Derajat Kejenuhan (Dj) terbesar terdapat pada simpang bersinyal Jl Mayjend Sungkono-Jl HR Muhammad yaitu 0,71 dan berkesimpulan bahwa ruas jalan dan kapasitas jalan masih bisa menampung volume lalu lintas yang terjadi. Jumlah bangkitan kendaraan akibat Mall Lagoon Avenue Sungkono adalah 104 kend/jam untuk MP dan 150 kend/jam untuk SM yang diperoleh dari hasil perhitungan yang didapatkan kesimpulan bahwa kapasitas jalan masih bisa menampung volume lalu lintas pada persimpangan dan ruas jalan di sekitar lokasi sehingga tidak terlalu berdampak pada lalu lintas tersebut. Pada tahun 2018 dan atau kondisi eksisting belum perlu dilakukan perbaikan kinerja simpang bersinyal karena kapasitas jalan masih memenuhi volume kendaraan dengan $\mathrm{Dj}$ paling tinggi 0,84 .

Dalam perencanaan pembangunan pada suatu kawasan dan perencanaan tata ruang suatu kawasan hendaknya selalu berhubungan dengan perencanaan jaringan transportasi kawasan tersebut, sehingga dampak lalu lintas yang timbul dapat diminimalkan dan memudahkan dalam penanganan kinerja lalu lintas. Dalam proses penelitian, pengamat melakukan pengukuran kecepatan dengan metode yang menggunakan alat bantu stopwatch dan counter, pengamat sangat mengandalkan kesigapan dan ketepatan sehingga diperlukan metode pengukuran yang lebih baik. Volume lalu lintas pada tahun-tahun berikutnya setelah beroperasinya Mall Lagoon Avenue Sungkono pada Persimpangan Jl Mayjend Sungkono-HR Muhammad pasti akan terus bertambah sehingga perlu dilakukan upaya perbaikan, baik dari waktu siklus, rambu dan ataupun marka simpang bersinyal.

\section{DAFTAR PUSTAKA}

Badan Pusat Statistik Surabaya. (2015). Statistik Indonesia Tahun 2015. Surabaya: Badan Pusat Statistik.
Black, A. (1981). Urban Transport Planning-Theory and Practice. AMER PLANNING ASSOC 1313 EAST 60 STREET, CHICAGO, IL 60637-2891.

Departemen Perhubungan. (1996). Keputusan Direktur Jendral perhubungan Darat Tentang Pedoman Teknis Penyelenggaraan Fasilitas Parkir. Jakarta.

Kurniawan, F., Mudjanarko, S. W., \& Ogunlana, S. (2015). Best practice for financial models of PPP projects. Procedia Engineering, 125, 124-132.

Lestari, F. A., \& Apriyani, Y. (2014). Analisis Dampak Lalu Lintas Akibat Adanya Pusat Perbelanjaan Dikawasan Pasar Pagi Pangkalpinang Terhadap Kinerja Ruas Jalan. In Forum Profesional Teknik Sipil (Vol. 2). Universitas Bangka Belitung.

Mudjanarko, S. W., \& Sulistio, H. (2013). Behaviour Model of Motor Cycle User in Selecting Parking Location (Case study in Surabaya City of Indonesia). Journal of Basic and Applied Scientific Research (JBASR), 3, 842846.

Rantung, T., Sompie, B. F., \& Jansen, F. (2015). Analisa Dampak Lalu Lintas (Andalalin) Kawasan Lippo Plaza Kairagi Manado. Jurnal Ilmiah Media Engineering, 5(1).

Sumajouw, J., Sompie, B. F., \& Timboeleng, J. A. (2013). Analisis Dampak Lalu Lintas (Andalalin) Kawasan Kampus Universitas Sam Ratulangi. Jurnal Ilmiah Media Engineering, 3(2).

Tamin, O. Z. (2000). Perencanaan dan pemodelan transportasi. Penerbit ITB.

Yulmida, D., Mudjanarko, S. W., Setiawan, M. I., \& Limantara, A. D. (2017). Analisis Kinerja Parkir Sepanjang Jalan Walikota Mustajab Surabaya. U KARST, 1(1). 